Case Report

\title{
A Case of Bisphosphonate-Related Osteonecrosis of the Jaw in a Patient with Subpontic Osseous Hyperplasia
}

\author{
Chiaki Tsuji, Hiroshi Watanabe, Hidenori Nakayama, Mitsuo Goto, and Kenichi Kurita \\ Department of Oral and Maxillofacial Surgery, School of Dentistry, Aichi Gakuin University, Nagoya, Japan \\ Correspondence should be addressed to Chiaki Tsuji; chiatsuji@hotmail.com
}

Received 2 September 2016; Accepted 23 January 2017; Published 14 February 2017

Academic Editor: Asja Celebić

Copyright (C) 2017 Chiaki Tsuji et al. This is an open access article distributed under the Creative Commons Attribution License, which permits unrestricted use, distribution, and reproduction in any medium, provided the original work is properly cited.

\begin{abstract}
Subpontic osseous hyperplasia ( $\mathrm{SOH}$ ) is a growth of bone occurring on the edentulous ridge beneath the pontics of fixed partial dentures (FPDs). This report describes a case of bisphosphonate- (BP-) related osteonecrosis of the jaw (BRONJ) in a SOH patient followed by deciduation of the bony lesion. A 73-year-old woman visited a dental clinic after experiencing pain and swelling beneath the pontics of a FPD that had been inserted 15 years ago. The pontics were removed, but the symptoms persisted and she was referred to our hospital. There was an osseous bulge and gum swelling around the edentulous ridge of teeth 18 and 19 , as well as bone exposure. As she had been taking an oral BP for 6 years, we diagnosed this case as stage 2 BRONJ. Following BP withdrawal, the bony lesion detached from the mandible. The tissue was diagnosed as sequestrum based on the histopathological findings. Two months after deciduation, epithelialization over the area of exposed bone was achieved and no recurrence has been observed.
\end{abstract}

\section{Introduction}

Fixed partial dentures (FPDs) with pontics are commonly used to replace missing molars. Osteoblastic deformation occurring under pontics was first introduced as subpontic osseous hyperplasia (SOH) by Calman et al. in 1971 [1]. Since then, many studies have investigated $\mathrm{SOH}$. The condition is normally discovered when individuals wearing FPDs for several years undergo simple radiography because of discomfort and pain at FPD sites. Many patients with $\mathrm{SOH}$ undergo surgical resection because the spontaneous detachment of hyperplastic bone has not been reported previously. Here, we report a rare case of detachment of hyperplastic bone in a patient with $\mathrm{SOH}$ leading to bisphosphonate-related osteonecrosis of the jaw (BRONJ).

\section{Case}

2.1. Patient. The patient was a 73-year-old woman.

2.2. First Examination. The first examination was carried out in June 2012.
2.3. Chief Complaints. The patient complained of dull pain in the left mandible.

2.4. Past Medical History. Past medical history included hypertension, paroxysmal atrial fibrillation, cerebral infarction, and osteoporosis.

2.5. Present Medication. The present medication included aspirin, amlodipine besylate, cimetidine, gloriamin, and alendronate sodium hydrate (ASH), which had been taken for 6 years since May 2006.

2.6. Current Medical History. In May 2012, she felt pain and noticed gingival swelling under the pontic in the mandibular FPD that had been placed in another dental clinic 15 years earlier. Serial radiographic images taken by the former dentist revealed subpontic bone formation (Figure 1).

The pontic was removed by the dentist in early June 2012, and the patient was followed up. However, the patient was referred to our department for a comprehensive examination in late June 2012 because of the lack of improvement in pain and swelling. 


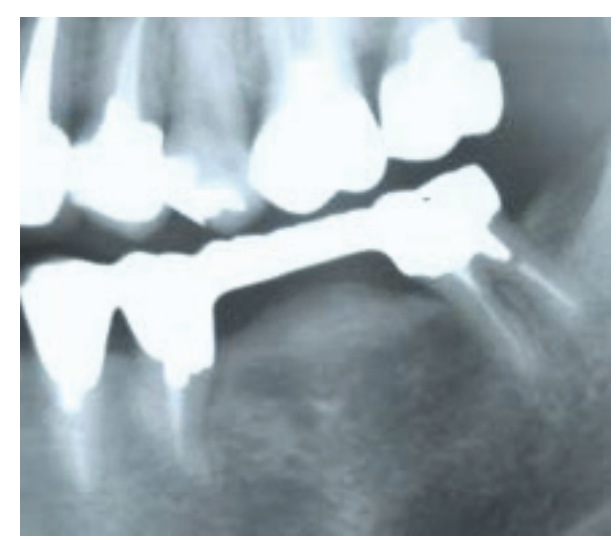

(a)

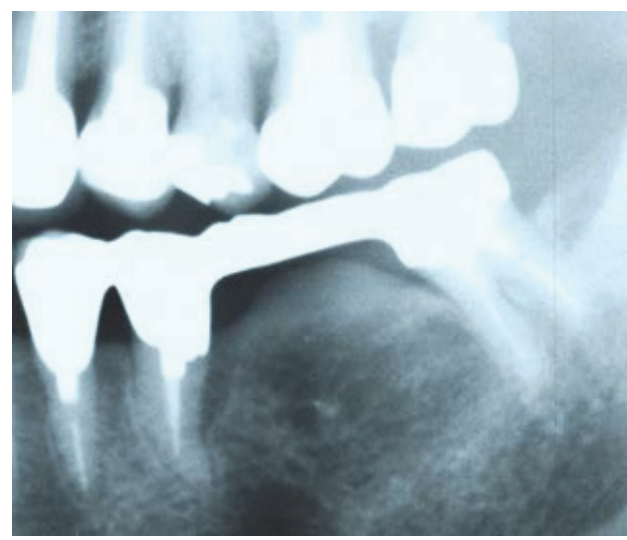

(c)

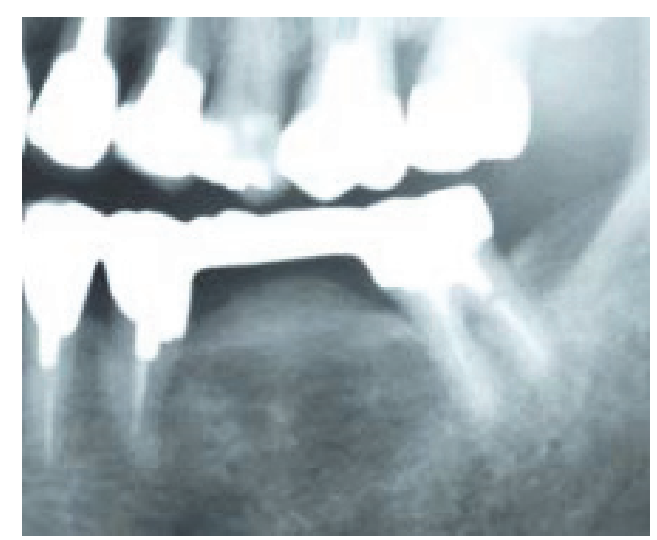

(b)

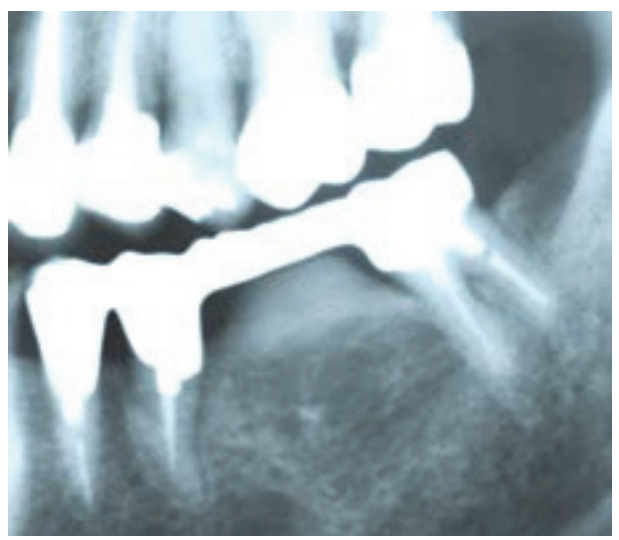

(d)

FIgURE 1: Panoramic radiographic images. (a) Image taken in October 2002 (before starting the oral bisphosphonate [BP]). (b) Image taken in February 2005 (before starting the oral BP). (c) Image taken in September 2008 (1 year and 4 months after starting the oral BP). (d) Image taken in September 2011 (5 years and 4 months after starting the oral BP). These images show chronological changes in the subpontic bone formation.

\section{Present Symptoms}

3.1. Extraoral Findings. Extraoral findings were unremarkable.

3.2. Intraoral Findings. In the alveolar crest of the lower left teeth 18 and 19 , a $10 \times 11 \mathrm{~mm}$ protrusion was accompanied by the exposure of bone approximately $3 \mathrm{~mm}$ in diameter, gingival swelling, and discharge of pus (Figure 2).

3.3. Imaging Findings. Panoramic radiographic images taken in the first examination revealed a radiopaque area, resembling cortical bone, with moderately demarcated but distinct borders in the alveolar crest of the lower left teeth 18 and 19 (Figure 3).

Computed tomography revealed similar findings indicative of osteosclerosis (Figure 4).

3.4. Clinical Diagnosis. Hyperostosis and BRONJ of the alveolar bone at lower left teeth 18 and 19 were suspected.

3.5. Treatment and Disease Course. The bone was exposed for 9 weeks. Because the patient had taken oral ASH for 6 years

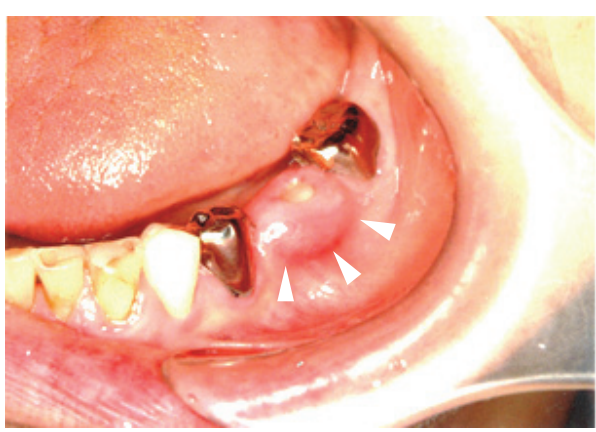

FIGURE 2: Intraoral photographic image taken in the first examination. The bone is exposed from the alveolar crest of the lower left teeth 6 and 7, with swelling and redness in the surrounding gingiva.

with no history of radiotherapy to the mandible, we made a diagnosis of stage 2 BRONJ. To treat inflammation, the patient was prescribed the antibiotic clarithromycin for 7 days and was instructed to continuously gargle $0.2 \%$ benzethonium chloride mouthwash solution (Neostelin Green $0.2 \%$, Nishika). ASH was discontinued because the patient had a 


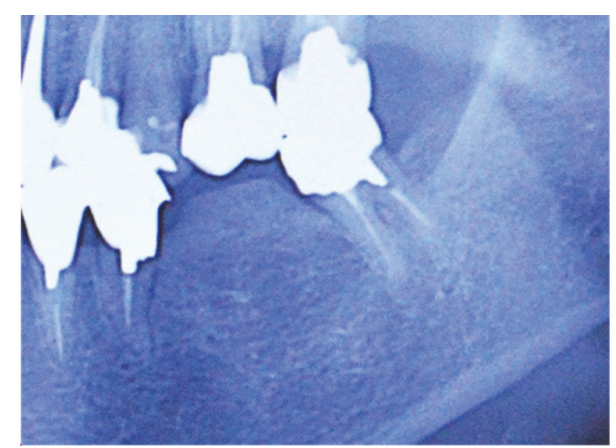

FIgure 3: Panoramic radiographic image taken in the first examination. Radiopaque area in the alveolar crest of lower left teeth 6 and 7 , showing osteosclerosis and formation of bone resembling cortical bone.

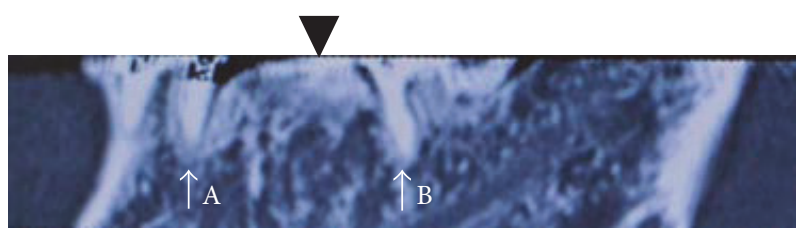

FIGURE 4: Sagittal computed tomographic image. Arrows: (A) the root of the lower left tooth \#4 and (B) the root of the lower left tooth \#8. Arrowhead: bone formation.

low risk of bone fracture from osteoporosis according to a plastic surgeon who we consulted, and the patient was scheduled to undergo plastic surgery to resect the bone 3 months later. However, she visited our department in November 2012 and brought in bone tissue that had spontaneously detached. Examination revealed that the area from which the tissue had detached was almost completely covered by the gum and had no discharge of pus (Figure 5).

Two months later, the original area of bone exposure was completely covered by the epithelium (Figures 6 and 7).

3.6. Histopathological Findings. The bone tissue had a compact laminated structure and did not contain the cellular components of bone, but, instead, a bacterial mass was observed inside the tissue (Figures 8 and 9).

3.7. Histopathological Diagnosis. The histopathological diagnosis was sequestrum.

\section{Discussion}

Since its first report by Calman et al. [1] in 1971, 62 studies have investigated $\mathrm{SOH}$, revealing that it commonly occurs unilaterally in the mandibular area that is missing molars and that only two maxillary cases have been reported previously $[2,3]$. FPDs often develop in patients who have been wearing dentures for over 3 years, but it can occur in those wearing the denture for less than 1 year [4], with a mean duration of 13 years [5]. The mean age of onset is 56.6 (range: 29-81) years, with no differences by age group or sex [5]. Although a previous study by Islam et al. [6] investigated $\mathrm{SOH}$ among

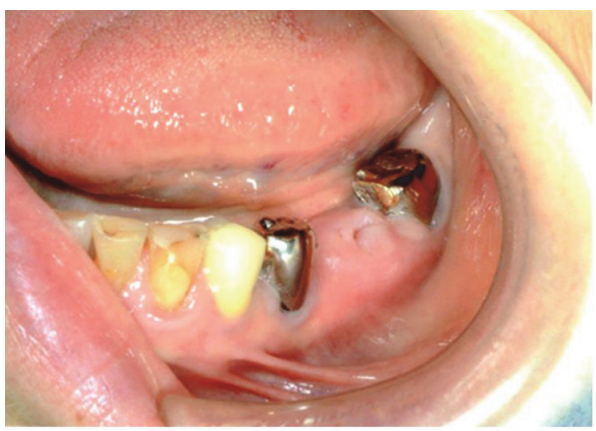

FIGURE 5: Intraoral photographic image after detachment of the sequestrum. Epithelialization was underway with no exposed bone.

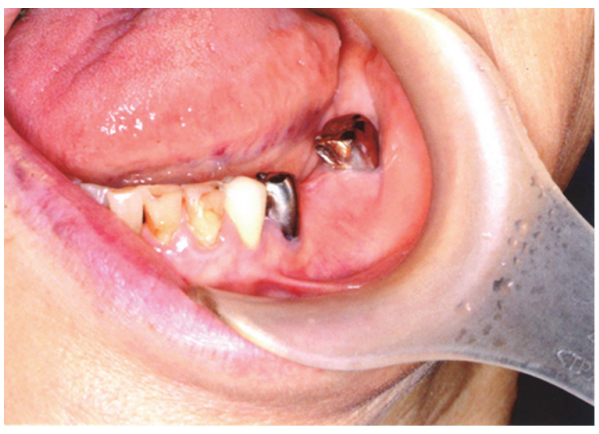

FIGURE 6: Intraoral photographic image taken 2 months after exfoliation. Epithelialization was observed, with no signs of inflammation in the surrounding mucosa.

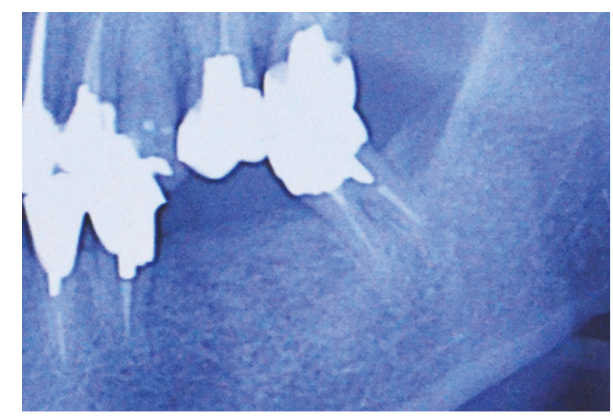

FIgURE 7: Panoramic radiographic image taken 2 months after exfoliation. No recurrence of bone formation was observed.

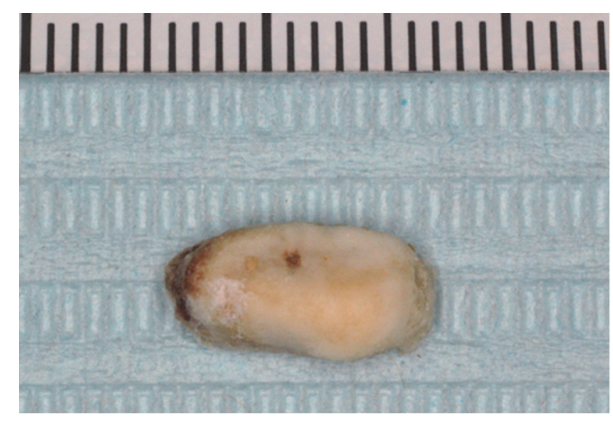

FIGURE 8: Spontaneously detached sequestrum. 


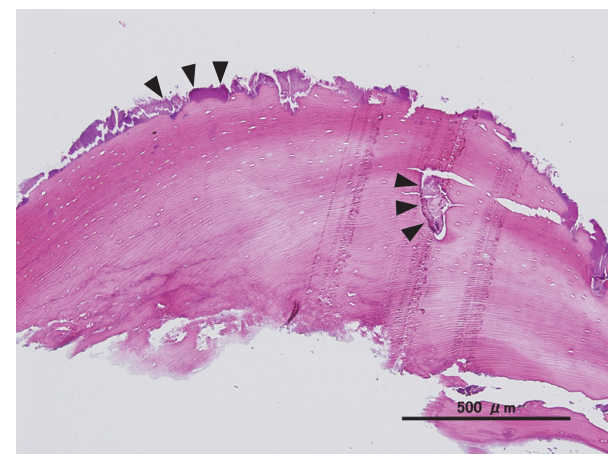

FIGURE 9: Histopathological findings (hematoxylin and eosin stain, slight magnification). Bone tissue, consisting of compact laminated structures, is void of cellular components but contains bacterial masses (arrow).

patients taking oral BP, the details of the disease course are currently unclear. Our patient developed $\mathrm{SOH}$ and had taken BP for 6 years before the bone became exposed for 9 weeks, as shown in Figures 1(a) and 1(b). In addition, the patient had not received radiotherapy to the mandible. Therefore, this appears to be a rare case of $\mathrm{SOH}$ accompanied by BRONJ.

The possible causes of $\mathrm{SOH}$ include generic components, chronic stimuli, or mechanical stresses. In patients wearing FPDs, the loading of occlusal force onto abutment teeth and surrounding bone tissue is thought to induce bone formation [6], and this hypothesis is supported by the fact that the removal of FPDs sometimes leads to the reduction of $\mathrm{SOH}$ $[3,6]$. Similar mechanisms may be involved in this study. It is interesting to observe the progression of bone formation even after commencement of the oral BP, as shown in Figures 1(c) and $1(\mathrm{~d})$, but the involvement of the BP in bone formation in this case is currently unclear.

The mechanism of BRONJ is unclear in the present $\mathrm{SOH}$ case, but in the areas where the tori and mylohyoidean line are present, the mucosa is thin and susceptible to development of a decubitus ulcer and is a common site for BRONJ. Similarly, in our patient, the exposure of bone and the development of BRONJ appeared to have been caused by the pontic repeatedly stimulating the mucosa that had been thinned by the $\mathrm{SOH}$. Considering that previous studies of $\mathrm{SOH}$ did not reveal the spontaneous exposure of bones, it is possible that $\mathrm{BRONJ}$ occurred with $\mathrm{SOH}$ in the present case. The mechanism may also have involved the suppression of osteoclasts and osteoblasts by the BP, exacerbation of oral infection, suppression of neovascularization, vascular obstruction, lowered blood flow, proliferation of epithelial cells, inhibition of leukocyte migratory ability, osteosclerosis, or immune compromise [7].

The spontaneous detachment of sequestrum has not been observed in $\mathrm{SOH}$ but occurs often in BRONJ [8]. Therefore, it appears that bone formation in $\mathrm{SOH}$ progressed into BRONJ because the pressure to the mucosa exerted by the pontic caused circulation impairment and then necrosis of the mucosa. The natural detachment of sequestrum was thought to be caused by a reduction in the effect of the $\mathrm{BP}$ after its discontinuation, causing the sequestrum to
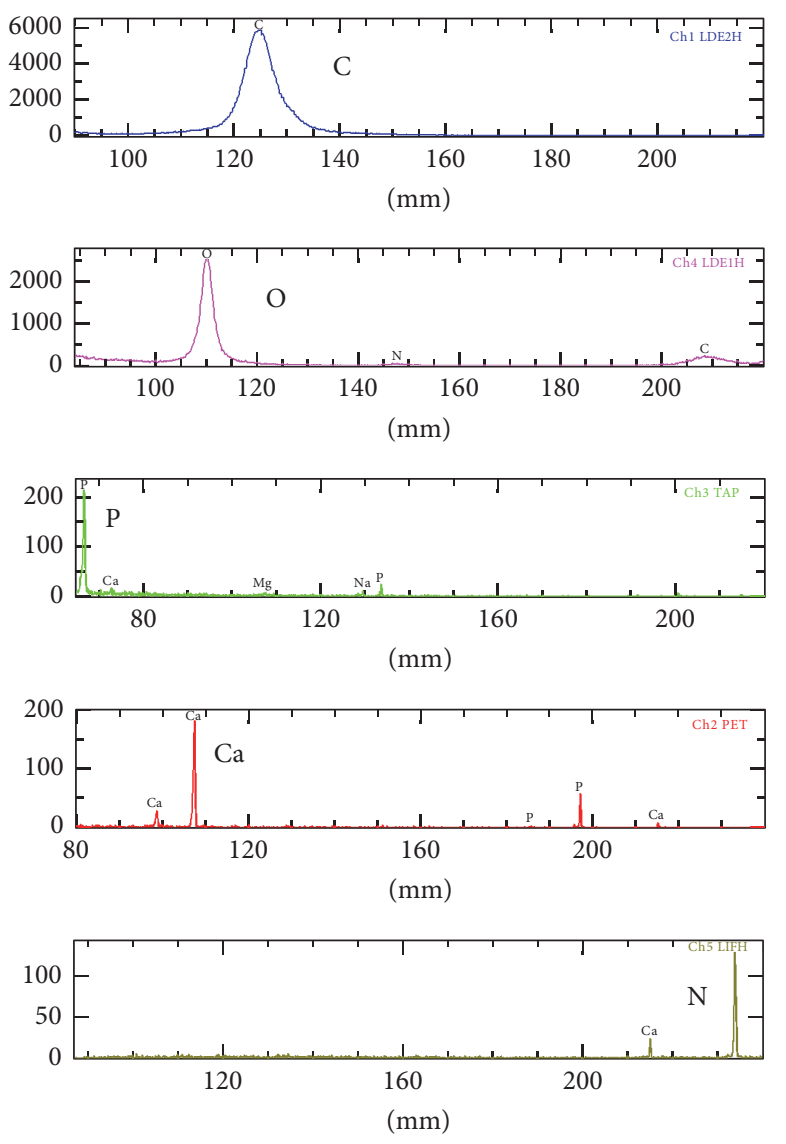

FIgUre 10: Analysis of bone composition. Cellular compositions were similar to those observed in normal bone tissue.

separate from the laminated bone. Although we analyzed the separated sequestrum, the compositions were similar to those in normal bone tissue, revealing no relationship with the $\mathrm{BP}$ (Figure 10).

In simple radiography, the specific features of $\mathrm{SOH}$ are an increase in subpontic radiopacity, osteosclerosis of cortical bone, and a mixture of radiopacity and radiotransparency $[3,5]$. Although the radiographic findings of BRONJ vary by stage, they are characterized by radiolucent, radiopaque, or mixed poorly demarcated patches. In the advanced stages, osteosclerosis, irregular bone surface, and the separation of sequestrum are observed [7]. In this study, simple radiographic images taken 10 years earlier at the former clinic revealed an increase in the radiopacity of the subpontic cortical bone in the alveolar crest. Although radiolucent patches were absent, the osteosclerosis continued to grow with time, resulting in imaging findings consistent with those of either SOH or BRONJ.

The histopathological findings of resected $\mathrm{SOH}$ specimens include mature laminated bone layers with osteocytes and exostosis-like proliferation resulting in Haversian canals [6, 9-11], similar to those observed in this study. On the other hand, the histopathological findings of BRONJ are characterized by sequestrum, agglomeration of microorganisms, and necrotic tissue filled with neutrophils and other cells, with 
no specific histopathological findings. As a result, BRONJ is often reported as osteomyelitis or sequestrum [12]. In this study, the sequestrum had laminated bone tissue containing bacterial aggregations, and, based on the histopathological findings, we thought that this was a case of $\mathrm{SOH}$ that turned into BRONJ.

\section{Conclusion}

Here, we reported a rare case of BRONJ where the formed bone in a patient with $\mathrm{SOH}$ spontaneously detached.

\section{Competing Interests}

No competing interests are declared in this study.

\section{References}

[1] H. I. Calman, M. Eisenberg, J. E. Grodjesk, and L. Szerlip, "Shades of white. Interpretation of radiopacities," Dental Radiography and Photography, vol. 44, pp. 3-10, 1971.

[2] K. B. Frazier, P. S. Baker, R. Abdelsayed, and B. Potter, "A case report of subpontic osseous hyperplasia in the maxillary arch," Oral Surgery, Oral Medicine, Oral Pathology, Oral Radiology, and Endodontics, vol. 89, no. 1, pp. 73-76, 2000.

[3] U. Aydin, D. Yildirim, and E. Bozdemir, "Subpontic osseous hyperplasia: three case reports and literature review," European Journal of Dentistry, vol. 7, no. 3, pp. 363-367, 2013.

[4] E. J. Burkes, D. L. Marbry, and R. E. Brooks, "Subpontic osseous proliferation," The Journal of Prosthetic Dentistry, vol. 53, no. 6, pp. 780-785, 1985.

[5] C. A. Lee, M. B. Lee, C. R. Matthews, and D. N. Takakis, "Subpontic osseous hyperplasia: a case series and literature review," General Dentistry, vol. 62, pp. 46-52, 2014.

[6] M. N. Islam, D. M. Cohen, M. T. Waite, and I. Bhattacharyya, "Three cases of subpontic osseous hyperplasia of the mandible: a report," Quintessence International, vol. 41, pp. 299-302, 2010.

[7] Y. Imai, "Osteonecrosis of the jaw that cannot be overlooked in prosthodontic treatment-new findings of BRONJ/ARONJ relevant to bone resorption inhibitors-," Annals of Japan Prosthodontic Society, vol. 6, pp. 233-241, 2014.

[8] S. L. Ruggiero, T. B. Dodson, J. Fantasia et al., "American association of oral and maxillofacial surgeons position paper on medication-related osteonecrosis of the jaw - 2014 update," Journal of Oral and Maxillofacial Surgery, vol. 72, no. 10, pp. 1938-1956, 2014.

[9] E. R. Lorenzana and W. W. Hallmon, "Subpontic osseous hyperplasia: a case report," Quintessence International, vol. 31, no. 1, pp. 57-61, 2000.

[10] W. C. Daniels, "Subpontic osseous hyperplasia: a five-patient report," Journal of Prosthodontics, vol. 6, no. 2, pp. 137-143, 1997.

[11] E. Nagahama, Y. Hamada, T. Kondoh, K. Murakami, T. Nakajima, and K. Seto, "A case of subpontic osseous hyperplasia of the mandible," Japanese Journal of Oral and Maxillofacial Surgery, vol. 47, no. 10, pp. 627-629, 2001.

[12] T. Ikeda and A. Yamaguchi, "Bisphosphonate-related osteonecrosis of the jaw: review from pathological observation," Japanese Journal of Oral and Maxillofacial Surgery, vol. 56, no. 6, pp. 352-356, 2010. 


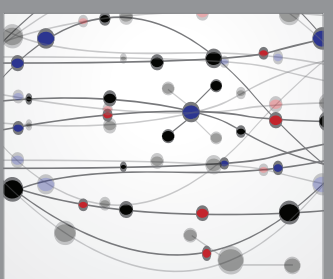

The Scientific World Journal
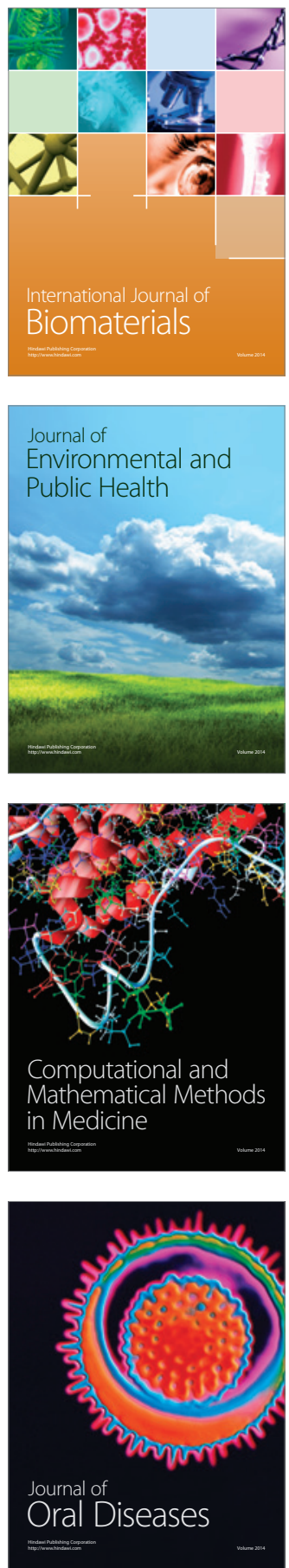
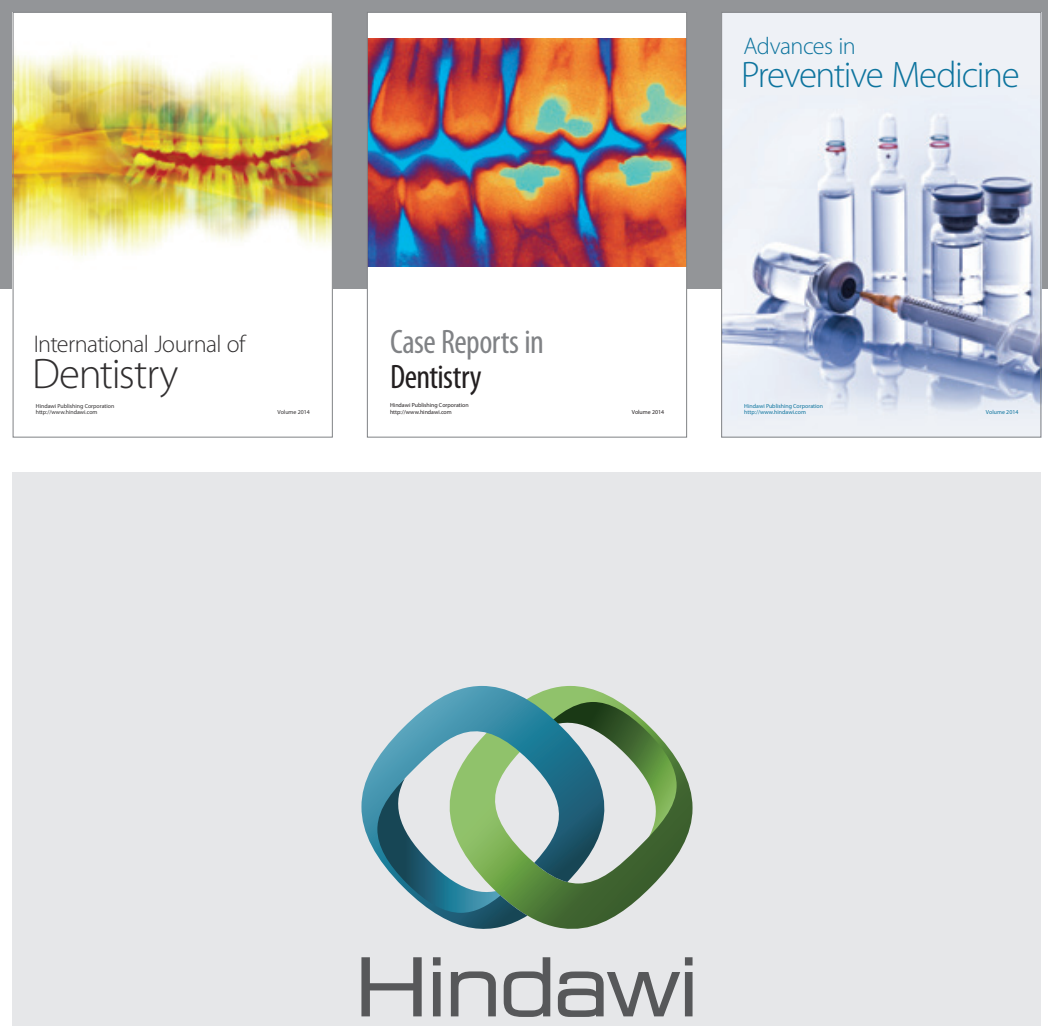

Submit your manuscripts at

https://www.hindawi.com
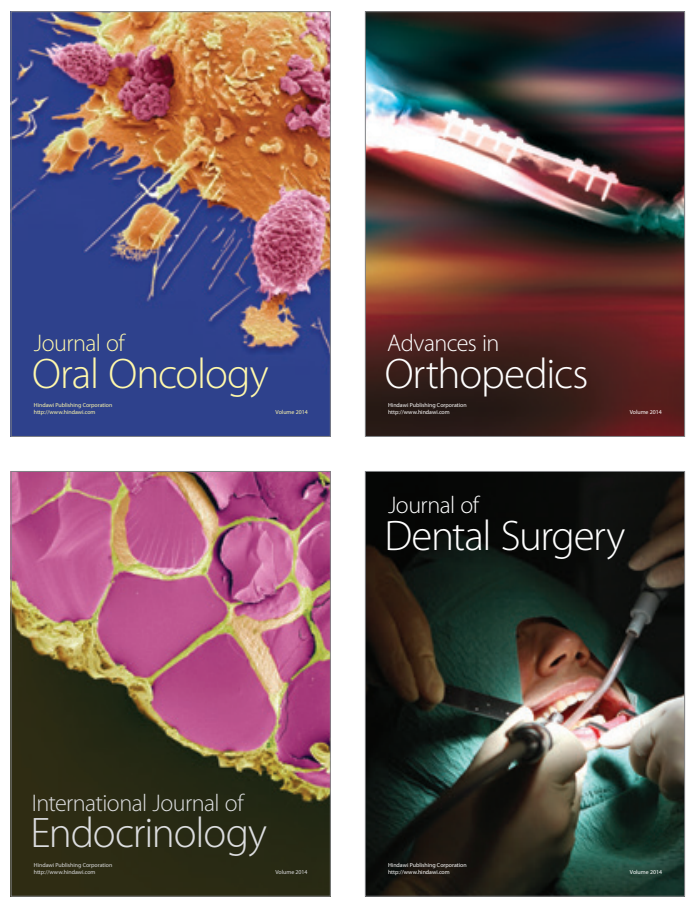
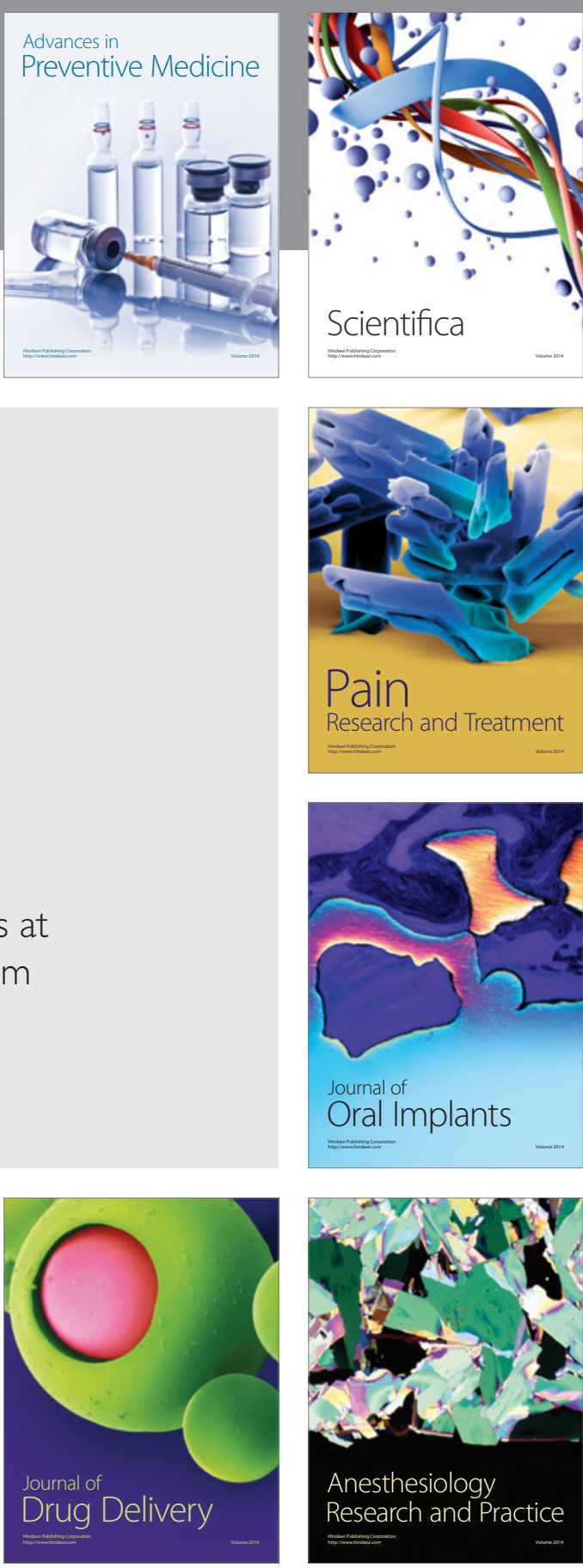

Scientifica
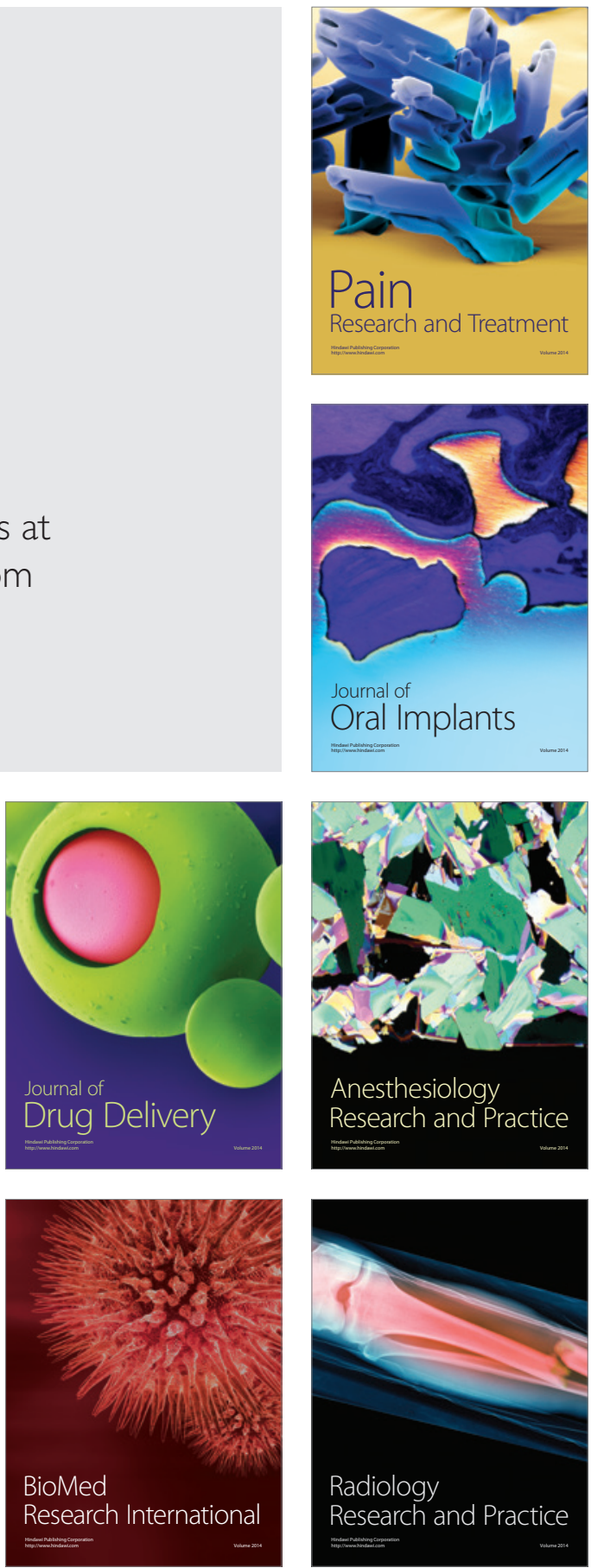